\title{
Arrest Avoidance: Law Enforcement and Price of Cocaine
}

\author{
Beth A. Freeborn \\ College of William and Mary
}

College of William and Mary

Department of Economics

Working Paper Number 30

June 2006

I would like to thank Peter Reuter, Ilyana Kuziemko, Ron Davies, Jeff DeSimone, Sarah Stafford, Carl Moody, Steven Stern and John Pepper for helpful comments on earlier drafts. All remaining errors are my own. 
COLLEGE OF WILLIAM AND MARY

DEPARTMENT OF ECONOMICS

WORKING PAPER \# 30

June 2006

\title{
Arrest Avoidance: Law Enforcement and Price of Cocaine
}

\begin{abstract}
Contrary to one goal of drug law enforcement, cocaine prices decreased between the years 1986 and 2000. This paper discusses how arrest avoidance behavior can affect cocaine consumer and dealer response to law enforcement. Dealers may avoid arrest by incurring quick and easy sales; thus pure gram price is negatively related to dealer enforcement. Consumers avoid arrest by accepting high prices rather than search for lower prices. Thus pure gram price is increasing in consumer enforcement. Because the implications from arrest avoidance conflict with traditional models of how enforcement should affect prices, I study the relationship using empirical analysis. Using purchase level data from the Drug Enforcement Administration and legal penalty data, I find a negative and significant relationship between dealer enforcement and pure gram price, which is consistent with the intuition of arrest avoidance.
\end{abstract}

JEL Codes: I1, K4, L2

Keywords: Drug law enforcement; Incarceration; Drug prices; Arrest Rates

Beth A. Freeborn

Department of Economics

College of William and Mary

P.O. Box 8795

Williamsburg, VA 23187-8795

bafree@wm.edu 


\section{Introduction}

Although the last two decades have seen an increase in the number of arrests and incarceration of drug offenders, the pure gram price of cocaine has dropped dramatically during this time period. ${ }^{1}$ If one goal of law enforcement is to increase the price of drugs such as cocaine, the dramatic decrease in pure gram price of cocaine may at first glance signal that current policy is failing that mission. The traditional economic argument for increasing enforcement efforts directed at dealers is to increase the costs to sellers of illegal drugs. Dealers should then pass the increased costs of dealing illicit drugs on to consumers in the form of higher prices and consumption will fall.

Policymakers and economists have offered a number of possible supply-oriented explanations for why pure gram price has fallen, including improvements in production technology and smuggling capabilities. ${ }^{2}$ Although changes in pure gram price may arise due to changes in the dealer environment, prices are also affected by factors in the consumer environment. Most empirical literature on drug markets assumes that enforcement increases price through a dealer effect and focuses on estimating the elasticity of demand for illegal drugs. ${ }^{3}$ However enforcement increased for drug consumers during the 1980s and 1990s as well. Traditional supply and demand analysis where enforcement acts as a fixed cost to both sides of the market implies that consumption decreases; the theoretical effect on price is ambiguous.

Previous research has considered a general level of enforcement without separating consumers from dealers. Since enforcement on consumers and dealers may have opposing effects on pure gram price, empirical research should allow consumer-side enforcement to have a separate effect on the illegal drug market. This paper allows enforcement to separately affect dealers and consumers and also introduces an alternative response to enforcement - arrest avoidance behavior.

\footnotetext{
${ }^{1}$ For information on the movement of price and purity of illicit drugs, see Office of National Drug Control Policy (2004).

${ }^{2}$ See National Research Council (2001), pp 151-156. This research utilizes a fixed effects method to capture some of the technological change that may be occurring over this time period.

${ }^{3}$ Drug research focuses largely on cocaine and heroin because there is data available on package characteristics (the price paid for a package and the weight and purity level of that package). DiNardo (1993), and Saffer and Chaloupka (1995) are examples estimating demand elasticity for illicit drugs. Grossman and Chaloupka (1998) apply a rational addiction model to demand for cocaine and estimate the long-run price elasticity of total consumption.
} 
To date only a few studies have examined the relationship between enforcement and drug prices and the research has produced limited results. Kuziemko and Levitt (2004) study the association between the street level price of a pure gram of cocaine and the certainty and severity of punishment. ${ }^{4}$ They find that a one-standard deviation increase in the certainty of punishment (measured as the number of per capita drug arrests) is associated with a 12-22\% rise in the street price of cocaine. The results for severity (the fraction of drug arrests which result in the criminal being sent to prison) are mixed and not statistically significant; the authors state that a one-standard deviation in severity is associated with prices that $2 \%$ lower to 9\% higher. In general, Kuziemko and Levitt (2004) argue that tougher enforcement is linked to higher pure gram prices.

Bushway, Caulkins and Reuter (2003) develop an empirical model of "expected costs" using a theoretical framework where increases in enforcement lead to increases in prices (i.e., dealers must be compensated for higher risks or longer prison sentences by receiving a higher retail price). The authors estimate an expected cost model and also attempt to replicate the results from Kuziemko and Levitts's deterrence model, using county-level enforcement variables. ${ }^{5}$ Using a simple deterrence model, the authors do not find evidence that increased enforcement has lead to increases in retail price. The expected cost model shows a small, but positive, relationship between expected sentence term and retail price. The coefficient on arrest rate is negative but not significant.

Enforcement may affect different dimensions of the retail market. The price of an illicit substance depends on the purity and weight of the substance. Although most research on drug markets focuses on the pure gram price of the drug, there are two studies that analyze enforcement effectiveness on variables other than pure gram price. Davies (2005) analyzes the effect of federal mandatory minimum sentences on the purity of cocaine and heroin and finds enforcement to be positively and significantly related to purity. ${ }^{6}$ Burrus (2005) presents

\footnotetext{
${ }^{4}$ Kuziemko and Levitt repeat their analysis using two different price indexes. One is the city-year averages created by Abt Associates and the other is a state-level price series estimated by regressing individual prices on the other characteristics of the packages. The authors limit cocaine purchases to be five ounces or less. Five ounces translates to 140 grams of cocaine and could potentially be considered wholesale rather than retail level purchases.

${ }^{5}$ Bushway, Caulkins and Reuter also restrict the retail prices to purchases made at the one ounce level (28 grams) or below in order to drop purchases made at the wholesale level.

${ }^{6}$ Davies (2005) uses a difference-in-differences approach and finds that the imposition of Federal manda-
} 
a theoretical equilibrium model where dealer penalties are only increasing in the weight of drugs sold and finds that increasing the certainty of punishment for either dealers or users increases the purity and quantity of drugs consumed. ${ }^{7}$

The traditional model of supply and demand with enforcement acting as a fixed cost implies that enforcement has opposing effects on pure gram price, and thus enforcement on dealers and consumers should be considered as separate factors. I propose an additional impact of enforcement within each side of the market - arrest avoidance. Rather than assuming enforcement is a fixed cost, I allow enforcement to act as a cost that is incurred during the transaction between dealers and consumers. Assuming exogenous and fixed demand for cocaine, the dealer is more successful in avoiding arrest if he limits the number of transaction attempts, which implies that pure gram price is decreasing in expected penalty for sale of cocaine. On the consumer side, if consumers search for the best cocaine to maximize the utility of consumption, the cost of searching is positively related to the level of law enforcement directed towards consumers. Assuming exogenous and fixed dealer behavior, a partial search model implies that consumer-side enforcement is positively related to the pure gram price accepted by consumers.

As discussed in greater detail in Section 2, adding arrest avoidance to dealer or consumer behavior generates conflicting signs for the relationship between enforcement and pure gram price. If dealers wish to avoid arrest, dealers lower prices to ensure easy sales. On the other hand, consumers accept higher prices in an effort to avoid arrest. With arrest avoidance, the response of pure gram price to an increase in enforcement is opposite for dealers and consumers. In addition, each agent's arrest avoidance behavior implies the opposite of the traditional theory of enforcement as a fixed cost. Determining the relationship between dealer or consumer enforcement and price requires empirical analysis as intuition does not provide a clear answer.

This study examines the relationship between pure gram price and dealer and consumer

tory minimum sentences increase cocaine purity by $23 \%$ and heroin purity by $43 \%$. Davies also shows a positive relationship between the variance of purity and the number of drug-related emergency room episodes.

${ }^{7}$ Burrus (2005) also models a retail market with dose-based (purity times weight) penalties. He finds that increasing the certainty of punishment under dose-based penalties decreases the purity and quantity of drugs consumed: a result that is more consistent with the goals of current U.S. drug policy. 
enforcement variables. Cocaine prices are gathered by undercover agents and informants. I find that harsher expected enforcement on dealers is associated with a negative and significant change in pure gram price. The coefficients on consumer enforcement variables are positive, but generally not significant. Previous research has not separated out the effect of enforcement on consumers from that of dealers.

The negative relationship between dealer enforcement and pure gram price differs from the work of Bushway et. al. (2003) and Kuziemko and Levitt (2004). There are a number of factors that differentiate this paper from previous work. First, rather than use city-level pure gram price data prepared by the consulting firm Abt Associates, this analysis uses the raw data collected by the Dug Enforcement Agency (DEA). ${ }^{8}$ Second, consumers and dealers are treated as different agents, and I separate out the enforcement variables by possession and trafficking. Third, future periods are discounted to allow for rational measures of severity of punishment. The method of penalty transformation is explained in section three.

The paper is organized as follows: Section two describes the framework of arrest avoidance for dealers and consumers. Section three describes the data used for analysis. Sections four and five present the results and test the sensitivity of this analysis. Section six concludes.

\section{Framework of Arrest Avoidance}

\subsection{Dealer Arrest Avoidance}

Traditional analysis treats law enforcement as a cost to the dealer and thus implies pure gram price is increasing with enforcement. Assuming enforcement enters only as a production cost ignores that a dealer may adjust his number of transactions in order to lower his expected cost.

Assume that the number of packages a dealer sells in the market is a function of his wholesale cocaine and the characteristics of the packages he offers. ${ }^{9}$ If the dealer chooses to produce bigger (heavier) and more pure packages, then he will not have as many to sell.

\footnotetext{
${ }^{8}$ Most of the research on price and purity of cocaine relies on city-level prices generated by Abt Associates. However, in 2004 a new price/purity series was developed by RAND for the Office of National Drug Control Policy using more sophisticated methodology. See ONDCP (2004) for more details.

${ }^{9} \mathrm{I}$ assume the wholesale amount is exogenous rather than model the decisions of both the retailer and wholesaler. In Freeborn (2003), each dealer receives some average wholesale amount, although a dealerspecific error allows for variation around the mean due to the wholesale-retailer relationship.
} 
If the dealer wants to offer a large number of packages, he will have to dilute and/or offer smaller (lighter) packages.

Next assume that dealer costs are a function of the number of packages. That is to say, the more packages a dealer has to sell, the more likely he is to be caught and face legal penalties. The dealer cannot alter the penalty for sale of cocaine nor can he affect the probability of arrest on any given approach to sell cocaine. The dealer can minimize the number of approaches necessary to sell his packages in order to avoid arrest. The following assumptions are necessary for the empirical analysis I use.

1. Each dealer $j$ offers one type of package and sells $N$ packages of identical price, weight and purity. While economies of scope are expected in production (which would lend argument to modeling dealers as multiproduct firms), an argument for single-product dealers is that there may be diseconomies of scope in the costs of transaction. ${ }^{10}$

2. Transformation of wholesale stock into retail cocaine packages is costless (i.e., I assume away the costs of diluting agents, packaging materials, etc.). Caulkins, Jonathan, Johnson, Taylor and Taylor (1999) find that packaging material represents less than 1 percent of the retail price of drugs sold.

3. The foregone wage is zero. This is equivalent to assuming that all dealers face the same foregone wage, regardless of labor market opportunities. It ignores the fact that if the outside option wage is high enough, the drug dealer would choose not to be a dealer. Levitt and Venkatesh (2000) show that the street-level drug dealers of a gang in Chicago earn roughly the minimum wage. Independent retail dealers (not affiliated with a gang) may earn a slightly higher wage. Labor costs estimated in Caulkins et. al (1999) account for 2.3 percent of the retail sales revenue.

The expected legal cost of selling cocaine is a function of the probability of being arrested for sale, the length of sentence the dealer will receive, and the number of opportunities for

\footnotetext{
${ }^{10}$ If the dealer has multiple package types, the length of time for a transaction is increased (imagine the dealer must show all available types to the consumer). With each package type the dealer offers to a consumer, the likelihood of incurring the penalty increases. If the dealer offers only one package type (the profit-maximizing package type), he makes a take-it-or-leave-it offer to the consumer regarding package characteristics. That minimizes the transaction time spent with the consumer (the most likely time for arrest).
} 
the dealer to be arrested (which depends on the number of packages a dealer sells). The probability of arrest is assumed to be constant for each interaction. Because I am studying behavior in the retail cocaine market, the penalty is not defined to be a function of weight or purity. ${ }^{11}$

The dealer faces the prospect of arrest each time he engages in illegal behavior. While holding cocaine bears some risk, the act of selling cocaine is the most likely opportunity for drug sale arrest. This means that the legal penalty is strictly increasing in the number of packages the dealer sells (because each sale is a transaction where the dealer may be arrested). If a dealer is selling an increasing number of packages, he is more likely to be identified as a 'big' dealer and attract the attention of law enforcement.

A dealer's profit is the revenue from selling cocaine minus the expected costs which are a function of the probability of arrest and the legal penalty for sale of cocaine. To lower the conditional probability of being arrested the dealer alters his choice of package so that the number of encounters made is minimized. In order to reduce the number of encounters, the dealer adjusts his package choice so that it is appealing to a greater proportion of consumers. Holding everything else constant, a dealer wishing to avoid arrest will increase the likelihood of selling his package of cocaine to a random consumer; thus the dealer decreases the price relative to the purity and weight.

\subsection{Consumer Arrest Avoidance}

Although previous research has not separated enforcement effects on dealers and consumers, traditional economic analysis would suggest consumer law enforcement is a demand shifter, implying that an increase in consumer-side enforcement decreases pure gram price. While some consumers may exit the cocaine market in response to increased enforcement, there may also be some consumers who alter their behavior within the market.

Consider the parallels of arrest avoidance to a simple consumer search model. The consumer searches for a package that will maximize her utility of consumption. There exists a fixed cost each time a consumer interacts with a new dealer. The consumer attempts to

\footnotetext{
${ }^{11}$ Federal (and some state) laws have penalties that are increasing in the weight of package sold. However, the weight thresholds necessary to trigger higher penalties occur at weights greater then the defined retail level. For this reason, I am able to define the penalty to be independent of weight.
} 
purchase a package that maximizes her utility while avoiding the cost of search.

First I assume that a consumer does not know the pure gram price of any one retailer, but rather knows the distribution of pure gram prices over dealers in her geographic area. The underlying assumption of this search model is that consumers learn all the characteristics of the package when they interact with a dealer, i.e., there is no asymmetric information on purity. ${ }^{12}$ Once she learns the price of one dealer, the consumer evaluates the potential benefit of meeting the next dealer (in the form of a better pure gram price) against the cost of finding the next dealer.

I define the search cost of cocaine consumers to be the expected value of law enforcement. Given a pure gram price from one dealer, the cost to the consumer of finding a new dealer and learning his pure gram price is the penalty for possession of cocaine conditional on being arrested for possession. For a given consumer, there exists a unique reservation value $R$ that divides available packages of cocaine into packages the she purchases and packages she does not purchase.

If the expected benefit of finding a better price outweighs the search cost, the consumer searches for the next dealer. If the cost of finding the next dealer outweighs the expected benefit, the consumer purchases the package with the known price. The reservation value is defined such that the expected gain from search is equal to the cost of search. If the cost of search increases, the consumer will alter her purchasing behavior.

Adding arrest avoidance in the form of consumer search implies that increasing levels of consumer enforcement result in consumers accepting higher pure gram prices because the reservation value decreases. If the consumer finds a dealer with a relatively high price and search costs (enforcement) are also high, the benefit of searching again is less likely to outweigh the cost. The consumer is more likely to purchase the high price package when the

\footnotetext{
${ }^{12}$ Although there is some doubt as to whether or not consumers actually know the level of purity prior to purchase, there is not currently a general consensus on how to appropriately treat purity. Caulkins (1994) argues that consumers have an expected level of purity that governs the price of a transaction and mean purity should be used to create prices. However, the widely used Abt Associates price series data (Rhodes, 1997) implicitly assumes that consumers know the purity at the time of the purchase. Most search literature assumes agents can perfectly observe characteristics when the good is sampled. A learning model where consumers gradually realize the true characteristcs of the product might be appealing to some consumerfirm relationships. However, the user-dealer relationship is too unstable to make the necessary assumptions for a learning model. For example, Riley (1997) reports the average cocaine consumer purchases from 10-20 different dealers.
} 
search costs are high than if search costs are low.

The implication of consumer arrest avoidance is that a consumer wishing to avoid arrest decreases the number of searches before she purchases a package. This implies the consumer purchases a relatively higher pure gram price package as consumer-side enforcement increases.

\section{Data Description}

To address the research question of how penalties affect pure gram price of cocaine, data are compiled from a number of sources. Dealer enforcement may have a positive impact on pure gram price (if penalties act as a fixed cost) or a negative impact (if dealers decrease price to avoid arrest). Enforcement on consumers also has potentially offsetting effects on pure gram price. Heavy possession penalties may push some consumers out of the market, thus decreasing pure gram price but the remaining consumers may avoid arrest by accepting higher priced packages. In order to determine the relationship, I require data on pure gram price and enforcement variables (including both length of sentence and the probability of arrest) for dealers and consumers.

I obtain data on the geographic distribution of package types and match this to the legal penalty associated with sale and possession of cocaine in that particular county. In order to create certain necessary variables for the probability of arrest for possession and sale of cocaine, data on drug consumption and population statistics are used.

\subsection{Purchase Data}

The Drug Enforcement Administration (DEA) initiated a program to collect and manage data on drug purchases and seizures in the late 1970's. The System to Retrieve Information from Drug Evidence (STRIDE) contains records of cocaine and heroin purchases and seizures in the United States. Every interaction between a DEA agent or informant that results in a purchase or seizure is recorded in the database. The purchase records include information regarding the drug's form (crack versus powdered cocaine), weight, purity, price, location and date of purchase. The purchase cost is the price for the observed/seized package of cocaine, and weight is the total weight of the package in grams.

The data used in this research is limited to retail level cocaine purchases from January 
Table 1: Summary Statistics of STRIDE Data

\begin{tabular}{lrrrr}
\hline \hline Variable & Mean & Standard Deviation & Minimum & Maximum \\
\hline Weight (grams) & 0.8891 & 1.0349 & 0.013 & 4.00 \\
Purity & 0.7374 & 0.2093 & 0.005 & 1.00 \\
Price $(\$)$ & 99.144 & 168.80 & 1.000 & 5000 \\
Price/Pure Gram & 244.03 & 585.20 & 0.529 & 17452.88 \\
\hline \hline
\end{tabular}

1986 through December 2000. I define a retail package of cocaine as any package weighing less than four grams. ${ }^{13}$ The STRIDE data reports the geographic location at a city level. However, the penalty data are collected at a larger level (county). Each city in the STRIDE data is matched to its county FIPS identifier. Once the data are matched to the legal penalties using county FIPS identifiers, the final data set includes 12885 observations spanning 191 counties (37 states) in the United States.

Table 1 provides descriptive statistics of the STRIDE data used for this analysis. The average retail package weight is 0.89 grams with a minimum weight of a single package of 0.013 grams. The lowest purity level is 0.5 percent and the highest is 100 percent pure. The average purity level of a package in the retail market is 74 percent. Price for a retail package of cocaine ranges from $\$ 1$ to $\$ 5000$ with an average price of $\$ 99 .{ }^{14}$

There is some concern that the STRIDE data does not represent a random sample of the distribution. ${ }^{15}$ Given the criticism of the data, analysis on the illicit drug market could be improved if there existed better data. ${ }^{16}$ However, currently STRIDE is the most complete and widely used data set available. Certainly researchers can learn something about the market using a sample of package characteristics observed in the market.

\footnotetext{
${ }^{13}$ There is no general consensus on what weight threshold determines the retail cocaine market. Three grams is equivalent to roughly ten usage sessions. Abt Associates (1997), Yuan and Caulkins (1998), Bushway et.al (2003) and Kuziemko and Levitt (2004) use 1, 3.5, 28 and 140 grams, respectively to define the retail market. The commonly used term "eightball" represents a package weighing 3.5 grams, or 1/8th of an ounce. I choose a slightly higher weight to include all eightballs and a few heavier observations.

${ }^{14}$ I exclude observations where pure gram price is greater than $\$ 20,000$ which eliminates 0.1 percent of the sample. Sensitivity of results to price outliers is discussed in the sensitivity analysis section of the paper.

${ }^{15}$ For example, there may be variation in the criteria to begin an investigation over time and across offices (e.g., DEA agents in port cities may be oriented towards large purchases or seizures and less concerned with the retail market). See Horowitz (2002).

${ }^{16}$ The Committee on Data and Research for Policy on Illegal Drugs concluded that there is a pressing need to improve existing data and acquire more reliable drug price data. Until more reliable data is gathered, the Committee report states the nation will continue to be poorly informed about the price of illegal drugs, total expenditure on illegal drugs and the effectiveness of intervention techniques. See National Research Council (2001).
} 


\subsection{Legal Penalty Data}

Agents consider the magnitude of the penalty as well as the probability of incurring the penalty. I collect prison and probation sentence length from the National Judicial Reporting Program (NJRP) to construct the penalty term. The data used to calculate arrest rates is collected from the Uniform Crime Reports (UCR) and supplemented with data from the National Household Survey on Drug Abuse (NHSDA) and Census data.

\subsubsection{Sentence Lengths: NJRP}

The penalty for selling cocaine at the retail level may be a minimum jail or prison sentence, community service, probation or a monetary fine. The National Judicial Reporting Program (NJRP) surveys a nationwide sample of county felony trial courts every two years and contains detailed information on demographic characteristics of felons, conviction offenses, type of sentences and sentence lengths. Drug offenses are split into drug trafficking and drug possession. ${ }^{17}$

I use the NJRP data to construct the county level median sentence and probation/parole length for both possession and sale of illegal drugs. ${ }^{18}$ In order to get an accurate measure of the sentence imposed for drug offenses, all felons with multiple offenses were dropped. This leaves observations of sentences of felons for whom the drug offense was the only crime of record. ${ }^{19}$

Table 2 presents summary statistics of drug offenders in the NJRP. Conditional on being arrested and found guilty (or reaching a plea agreement) for possession, 87 percent of consumers are sentenced to a term between one month and five years. Relative to consumers,

\footnotetext{
${ }^{17}$ Trafficking includes manufacturing, distributing, selling, smuggling, and possession with intent to sell as well as attempts to do any of the above. Possession includes possession of an illegal drug and attempts to possess an illegal drug, but excludes possession with intent to sell. The NJRP does not distinguish cocaine sentences from other drug trafficking and possesion sentences, although marijuana offenses are specially coded so they are dropped from the sample.

${ }^{18} \mathrm{I}$ use the median rather than the mean to avoid outliers biasing the statistic. For instance, some felons convicted of drug possession receive unusually long sentences. This may be due to a 'three strikes rule' or some factor that is unobserved in the data. Felon history is not reported in NJRP. I use the county level sentence data instead of state law mandates. Given that a dealer is considering his expected penalty, I assume dealers are more likely to know and react to the sentence history of their fellow drug dealers rather than the state legal code.

${ }^{19}$ The inclusion of sentences for all felons with any drug offence may overstate the drug-related sentence. The sentence would implicitly include time assigned for other offenses and it is impossible to identify what part of the sentence is due solely to the drug offense.
} 
Table 2: Summary Statistics of NJRP Data

\begin{tabular}{lcccc}
\hline \hline & $\begin{array}{c}\text { Sentence Length } \\
\text { (in years) }\end{array}$ & $\begin{array}{c}\text { Percentage } \\
\text { of Sample }\end{array}$ & $\begin{array}{c}\text { Mean } \\
\text { (in years) }\end{array}$ & $\begin{array}{c}\text { Standard } \\
\text { Deviation }\end{array}$ \\
\cline { 2 - 5 } Sale: & Life Sentence & 5.9 & Life & N/A \\
& 5-20 Years & 12.7 & 8.83 & 3.05 \\
Possession: & 1-5 Years & 70.8 & 1.55 & 1.27 \\
& Life Sentence & 2.2 & Life & N/A \\
& 5-20 Years & 4.9 & 9.25 & 2.85 \\
& 1-5 Years & 87.3 & 1.14 & 0.999 \\
\hline \hline
\end{tabular}

Note: These sentences do not include observations of felons convicted for marijuana offenses.

there are far fewer dealers receiving a similar sentence; seventy percent of sentences for sale are between one month and five years. A dealer is more likely to receive a longer sentence than a consumer; 12.7 percent of dealers and 4.9 percent of consumers receive a prison sentence of more than five years.

There is some concern that individuals sentenced for possession of drugs are in actuality drug dealers who have plea bargained down to a lesser crime in order to reduce the sentence. ${ }^{20}$ The NJRP provides no information on the existence of plea bargains, nor prior offenses which may also affect the sentence length an individual receives. This presents a problem in interpreting the sentence length for possession and is discussed further in the analysis section.

Table 3 presents the correlation matrix of the enforcement variables. Enforcement variables have been transformed to account for discounting of future periods as explained below. Note that probation is negatively correlated with prison sentence for both sale and possession. Counties with long prison sentences for dealers are likely to have short probation terms (and vice versa). Prison sentence is positively correlated across sale and possession (0.8333), implying that counties are generally consistent in the length of assigned sentences across drug offenses.

Agents in the model consider the sentence as a cost, however the cost is paid out over future periods (months of jail time). Dealers and consumers do not weigh a month in prison

\footnotetext{
${ }^{20}$ Sevigny and Caulkins (2004) find that 38.8 percent of federal and 21.7 percent of state simple possession offenders self-report having some involvement in the distribution of drugs.
} 
Table 3: Correlation Matrix of Enforcement Variable Medians

\begin{tabular}{|l|llll|}
\hline \hline & $\begin{array}{c}\text { Sentence } \\
(\text { Sale })\end{array}$ & $\begin{array}{l}\text { Sentence } \\
(\text { Possession) }\end{array}$ & $\begin{array}{l}\text { Probation } \\
(\text { Sale })\end{array}$ & $\begin{array}{l}\text { Probation } \\
\text { (Possession) }\end{array}$ \\
\hline Sentence (Sale) & 1.0000 & 0.8333 & -0.3903 & -0.1173 \\
Sentence (Possession) & 0.8333 & 1.0000 & -0.1666 & -0.1353 \\
Probation (Sale) & -0.3903 & -0.1666 & 1.0000 & 0.1315 \\
Probation (Possession) & -0.1173 & -0.1353 & 0.1315 & 1.0000 \\
\hline
\end{tabular}

served 20 years from now at the same value as a current month served in prison. Agents may consider a 75 year sentence and 100 year to be essentially equal, however the cost differences between a 12 month and 18 month sentence are quite different. I allow agents to discount the future value of months served, assuming both positive time preference and constant rate discounting. ${ }^{21}$ This changes the relative costs to agents (the cost of a 24-month sentence is not exactly twice the cost of a 12-month sentence). The prison sentences were transformed according to the function $S=\sum_{t=1}^{T} \beta^{t}$ where $T$ is the length of the sentence in months and $\beta=0.9$ is the discount factor. Probation terms were transformed in a similar way. The appendix describes this data transformation in more detail. Transforming the penalty lengths represents a deviation from other research and I test the sensitivity of the results to this transformation in section six.

The NJRP includes variables for both drug possession and drug sale penalties biannually for the years 1986-1998. Some counties do not report the statistics for every year of the NJRP, resulting in missing values. When the median sentence is matched to the purchase data from STRIDE, there are 1995 unique county-year combinations. However, if counties are consistent in the median length of sentences assigned to drug offenses, the median county sentence length over all reported years may be assigned to the missing years. I test the hypothesis that county sentencing behavior is stable over time. The hypothesis is accepted at the five percent level and the penalty data are matched to the purchase data using only county identifiers. The appendix provides a more detailed explanation of this hypothesis test.

\footnotetext{
${ }^{21}$ Although transformation of the sentencing data to present value has not occurred previously in the drug market research, a number of other fields of research accept discounting of future periods as routine practice. See Polinsky and Shavell (1999), Polinsky and Shavell (1997) and Listokin (2003) as examples of recent research in law and economics featuring discounting future periods of imprisonment.
} 
Table 4: Summary Statistics for Merged NJRP Data

\begin{tabular}{lrrrr}
\hline \hline Variable & Mean & Standard Deviation & Minimum & Maximum \\
\hline Possession Probation & 0.173 & 0.624 & 0.000 & 5.894 \\
Possession Sentence & 6.664 & 2.099 & 1.094 & 10.00 \\
Sale Probation & 0.040 & 0.265 & 0.000 & 2.485 \\
Sale Sentence & 9.678 & 0.877 & 3.228 & 10.00 \\
\hline \hline
\end{tabular}

Note: The penalty variables in the merged dataset have been transformed according to the methods described above and in Appendix B.

Table 4 presents the average median probation and median prison sentence for possession and sale of cocaine when matched with the STRIDE purchase data. Recall the enforcement variables presented are transformed according to the methods described above and so the means and standard deviations of these variables no longer represent months of sentence. This transformation makes it difficult to assess the relative sizes of the penalties beyond magnitude of the variable. On average, consumers receive longer probation terms than dealers and dealers receive a longer prison sentence than consumers.

\subsubsection{Probability of Arrest: Consumers and Dealers}

Dealers and consumers must believe there is some likelihood of arrest and receiving the penalty for their crime for enforcement to impact behavior.

The probability of arrest has been constructed in previous papers using a variety of methods. However, no estimate of probability of arrest is ideal because there is no clear data available on the number of dealers in a given market. DeSimone (2001) proxies the probability of arrest using the ratio of arrests to reported offenses. DeSimone and Farrelly (2001) proxy the probability of arrest as the number of arrests in a state divided by an estimated number of drug users in the state that year. Bushway et. al. (2003) proxy the probability of arrest as the ratio of arrests to an estimate of the number of dealers using data from the Drug Abuse Warning Network (DAWN) which tracks emergency room episodes involving different drugs. Kuziemko and Levitt (2004) construct their measure of certainty of punishment as the number of drug arrests per capita.

Each previous estimate of the probability of arrest is a ratio of the number of arrests divided by some measure of the market size. Using population as a proxy for the market 
size may underestimate the probability of arrest, as the large majority of the population are not involved in daily drug trade. However, using the number of reported offenses as a denominator may overestimate the probability of arrest, as there are very few reports of drug trade that do not result in an arrest. Bushway et. al. (2003) argue their city-level market size measure is superior to using per capita drug offenses because it is produced using the number of drug consumers reported in emergency room situations. However, this estimate of market size may be underestimated because emergency room episodes only capture the most severe cases of drug use. Also, the market size measure is at a city-level, and the numerator (the number of arrests from UCR) is given at a county level. The authors report that results were similar to using per capita drug arrests.

This study constructs a separate probability of arrest for possession and sale of cocaine to address concerns over some of the previous measures. The numerator for the probability of arrest for both dealers and consumers is collected from the FBI's Uniform Crime Reports (UCR) which provides number of arrests by offense. The denominator is defined as the number of potential arrests, or the number of encounters $E$ between consumers and dealers.

There does not exist any reliable measures of the number of dealers across counties. There is limited information on cocaine consumers from the National Household Survey on Drug Abuse (NHSDA) and I use this data to estimate the size of the consumer market. The number of consumers is estimated using the probability of consuming cocaine conditional on demographic characteristics derived using the NHSDA. ${ }^{22}$ The probability is then multiplied by the demographic characteristics of the county in order to generate the number of consumers in a county for a given year. ${ }^{23}$

I calculate the number of encounters as the number of cocaine consumers multiplied by the average number of purchases the average consumer makes. The average number of purchases is provided by a supplemental study within the Arrestee Drug Abuse Monitoring

\footnotetext{
${ }^{22}$ Another potential source of data on the demographic characteristics of cocaine users is the Arrestee Drug Abuse Monitoring (ADAM) data. The NHSDA produces a much lower estimate of the number of frequent users of cocaine than ADAM because it surveys households while ADAM respondants are current arrestees.

${ }^{23}$ I assume that demographic characteristics are useful for predicting cocaine usage and the probability of consumption conditional on characteristics is stable across counties. These assumptions are necessary because the NHSDA does not include geographic identifiers (other than a dummy variable for population of the MSA over one million). If the county of residence was observed for respondants in the NHSDA, a more reliable estimate of the number of consumers in a market for a given year could be constructed.
} 
(ADAM) study and acts as a scaling factor. ${ }^{24}$ Once the number of encounters is estimated, I compute the probability of arrest for possession. The appendix describes the data and method used to construct the number of cocaine consumers.

The method above addresses some concerns about previous measures, but has its limitations as well. The estimates of probabilities of arrest are most similar to DeSimone and Farrelly (2001) in that this research uses a measure of market size constructed from responses to the NHSDA. However, I use a linear probability model and census data to construct a probability of usage at a county level, then estimate the market size given county demographics. DeSimone and Farrelly (2001) construct the probability of arrest at a state level because the NHSDA data they use includes state identifier of respondents. The authors calculate the denominator by multiplying the unweighted percentage of state respondents who use the drug by the Census estimate of state population. The method of this research improves upon the earlier estimates by incorporating demographic characteristics to estimate the market size and also estimates the number of users at a county level rather than state level. Additionally, the results of the empirical analysis do not change qualitatively when arrests per capita are used.

\section{Analysis}

Pure gram price is determined through the interaction of consumers and dealers, and intuition does not provide a clear sign for how pure gram price responds separately to enforcement variables on either side of the market. This section presents results from a linear regression of pure gram price on both consumer and dealer enforcement variables to empirically test the relationship between enforcement and pure gram price. The pure gram price of the $j^{\text {th }}$ purchase in county $l$ in year $t$ is denoted by $\widetilde{p}_{l j t}{ }^{25}$

\footnotetext{
${ }^{24}$ See Riley (1997) for more information on this variable. Note that $\bar{n}=7.875$ is provided by ADAM, which focuses on recent arrestees. This particular report provides information on drug purchase and use patterns in six select cities. Powder cocaine users report mean number of purchases in the previous week ranging from 3 to 9 (depending on the city), and crack cocaine users report the mean number purchases ranging from 6 to 14 .

${ }^{25}$ Pure gram price is calculated by dividing the individual purchase-price by purchase-weight times purchase-purity for each observation. Each unique package indicates a unique dealer $j$. Recall the assumption that each dealer makes a single type of package.
} 
The coefficient estimates are reported in Table $5 .{ }^{26}$ The enforcement variables include the tranformed sentence variables and the probability of arrest for both dealers and consumers. The other covariates include the percentage black, percentage male, the percentage of the county that is between the ages of 16 and 20 years old, the percentage that have finished high school or completed a GED, the percentage that have never been married and the per capita income level. ${ }^{27}$ The linear regression is run with the errors clustered by county to allow for observations to be independent across counties but not necessarily within county.

The signs of the coefficient estimates on dealer enforcement variables reported in Table 5 do not entirely match the traditional theory of risks and prices which argues that dealers need to be reimbursed for high costs or long sentences, and thus prices should be higher when dealers face long expected sentences for selling cocaine. ${ }^{28}$ The dealer sentence length coefficient is positive as theory predicts, but not significant, while the coefficient on the arrest rate for sale of cocaine is negative and significant. The negative sign implies that tougher enforcement in the way of more dealer arrests is consistent with a low pure gram price. ${ }^{29}$ The coefficient estimate on probability of arrest is consistent with the implications of arrest avoidance. The reasoning is that the dealer wishes to avoid the penalty by decreasing the pure gram price of his package. If there is no haggling and buyers are quick to accept the low price, dealers will not incur failed encounters and the chance of arrest and receiving the penalty is smaller. The negative coefficient estimate does not contradict the theory that dealers must be reimbursed for high costs, but rather implies that the net effect of arrest avoidance and enforcement as a fixed cost is negative. ${ }^{30}$

Recall that consumer search implies a positive relationship between consumer-side en-

\footnotetext{
${ }^{26}$ Note that the $\mathrm{R}^{2}$ is small because there are no independent variables that vary within county or year. There are multiple observations of the dependent variable (pure gram price) with a county-year cell. The $\mathrm{R}^{2}$ could be improved by regressing the average pure gram price within a city-year on the independent regressors.

${ }^{27}$ The per capita income level data is collected from the Regional Economic Accounts prepared by the Bureau of Economic Analysis. The Regional Economic Accounts reports estimates of per capita personal income for every county in the United States annually beginning in 1969.

${ }^{28}$ See Reuter and Kleiman (1986).

${ }^{29}$ The negative coefficient on arrest rate for sale of cocaine is consistent with the results from Bushway, et al (2003).

${ }^{30}$ I perform a Wald test to show that the coefficients on the dealer sentence lengths are statistically different from the coefficient on the arrest rate for sale of cocaine. The coefficients are statistically different from one another at a $10 \%$ level. The coefficient for probabtion length is not statistically different from the coefficient for sentence length.
} 
forcement and pure gram price. Consumers are willing to accept higher pure gram prices when consumer-side enforcement is high. Traditional theory argues that consumer enforcement is negatively correlated with pure gram price as consumers exit the market in response to enforcement. The coefficient estimate on arrest rate for possession is positive but not significant. The coefficient estimates on sentence lengths for consumers are also positive but neither are significant. These positive coefficients do not contradict traditional theory but instead show that the overall impact of consumer-side enforcement on pure gram price may be positive. ${ }^{31}$ Recall that the sentence length for possession may be higher than the actual drug consumer sentence length due to the inclusion of some drug dealers who have plea bargained down to a possession offense. However, if I assume that the plea bargaining rate for those dealers is consistent across counties, then variation on the variable for possession sentencing can still be used to estimate the sign of the coefficient.

The analysis presented in Table 5 is similar to the work of Bushway, Caulkins and Reuter (2003). ${ }^{32}$ The authors report negative but not significant coefficients on dealer arrest rate and positive significant coefficients on expected sentence, which are consistent with their "expected cost" model. ${ }^{33}$ Given the intuition of dealer arrest avoidance, I expect and report negative coefficients on dealer arrest rate. However, the positive coefficient on the length of sentence for sale of cocaine is consistent with the theory of risks and prices that dealers must be compensated for higher costs. The signs of the coefficient estimates also differ from the results of Kuziemko and Levitt (2004). ${ }^{34}$ Kuziemko and Levitt proxy the certainty of

\footnotetext{
${ }^{31}$ Again a Wald test is performed to show that the coefficients on the consumer sentence lengths are statistically different from the coefficient on the arrest rate for possession of cocaine. The probation and sentence coefficients are both statistically different from the arrest rate at a $15 \%$ level. The coefficient for consumer probation length is not statistically different from the coefficient for sentence length.

${ }^{32}$ Although the analysis is similar, there are differences in the price data used. I do not use the city-level prices prepared by Abt Associates. Bushway et al (2003) also restrict the data to purchases made at the one ounce (28 grams) level or below in order to drop purchases made at the wholesale level. I define retail purchases to be a smaller set - only those packages with a weight of less than 4 grams.

${ }^{33}$ Bushway et. al. (2003) estimate several regression models using variations of dependent variables (retail cocaine price, retail-wholesale prices, logged price) for different time periods (1983-1996, 1990-1996). In general, the coefficients on expected prison sentence are not significantly different from zero until later time periods where the dependent variable is 'Retail - Wholesale Prices (1990-1996)'. The expected prison sentence variable used differs from what I define to be expected prison term. Bushway et. al. (2003) construct an expected sentence as the mean of the maximum sentence length for any individual with a drug charge multiplied by the median time actually served as a proportion of the maximum sentence for people released with at least one drug charge.

${ }^{34}$ Kuziemko and Levitt also define retail cocaine differently. They use city-year averages obtained from
} 
Table 5: Relationship between Pure Gram Price and Arrest Rate with Enforcement Variables

\begin{tabular}{|c|c|c|c|}
\hline \multirow[t]{8}{*}{ Agent: } & Enforcement Variable & "Estimate (1) & t-statistic \\
\hline & Percentage Black & $\begin{array}{l}-26.517 \\
(98.300)\end{array}$ & -0.27 \\
\hline & Percentage Male & $\begin{array}{l}-325.22 \\
(847.33)\end{array}$ & -0.38 \\
\hline & Percentage Aged 16-20 & $\begin{array}{l}-1199.3 \\
(906.95)\end{array}$ & -1.32 \\
\hline & Percentage HS Grad or GED & $\begin{array}{l}-62.225 \\
(403.92)\end{array}$ & -0.15 \\
\hline & Percentage Never Married & $\begin{array}{l}183.57 \\
(264.78)\end{array}$ & 0.69 \\
\hline & Per Capita Income & $\begin{array}{l}-0.0024 \\
(0.0015)\end{array}$ & -1.67 \\
\hline & Intercept & $\begin{array}{l}1120.8^{*} \\
(428.47)\end{array}$ & 2.62 \\
\hline \multirow[t]{3}{*}{$\underline{\text { Dealer }}$} & Median Probation (Sale) & $\begin{array}{l}25.573 \\
(22.257)\end{array}$ & 1.15 \\
\hline & Median Sentence (Sale) & $\begin{array}{l}12.294 \\
(10.396)\end{array}$ & 1.18 \\
\hline & Arrest Rate for Sale & $\begin{array}{c}-625.16^{*} \\
(346.55)\end{array}$ & -1.80 \\
\hline \multirow[t]{3}{*}{$\underline{\text { Consumer }}$} & Median Probation (Possession) & $\begin{array}{l}2.5308 \\
(16.310)\end{array}$ & 0.16 \\
\hline & Median Sentence (Possession) & $\begin{array}{l}4.8636 \\
(8.2526)\end{array}$ & 0.59 \\
\hline & Arrest Rate for Possession & $\begin{array}{l}260.46 \\
(171.36)\end{array}$ & 1.52 \\
\hline $\mathrm{R}^{2}$ & & 0.0217 & \\
\hline
\end{tabular}

Note: Year and state fixed effects are included but not reported. Errors are clustered at the county level.

*Significant at the 10 percent level. **Significant at the 5 percent level. 
punishment using per capita drug offense arrests and find a positive and significant coefficient for certainty on pure gram price. ${ }^{35}$ The signs of the coefficients presented in Table 5 do not change when the analysis is repeated using arrests per capita, although the significance increases slightly for the arrest variables.

\section{Sensitivity Analysis}

Table 6 presents the coefficient estimates on enforcement variables for different models to test the sensitivity of the results to variations on the data used in analysis.

There is no consensus on what weight threshold constitutes the retail cocaine market. In the previous section, I choose a weight less than 4 grams to indicate a retail package. To test the sensitivity of the results to this assumption, the analysis of Table 5 is repeated using observations of packages with a smaller weight threshold of 2 grams. The first column of Table 6 illustrates that the signs and significance of the expected enforcement coefficients remain the same. Only the coefficient on probability of arrest for sale of cocaine is significant at the five percent level.

There may be concern that the years used in this analysis contain periods of change within the markets. I run the same regressions presented in Table 5 for two subsets of years to test how sensitive the results are to the years of data included. Columns two and three of Table 6 present the coefficients on expected enforcement variables for the periods 1986-1996 and 1990-2000. The signs of the coefficients on enforcement variables do not change. The arrest rate for possession coefficient is positive and significant over the period 1986 - 1996 and the coefficient estimate on arrest rate for sale of cocaine is negative and significant at the five percent level for the later time period.

Current research has analyzed the pure gram price of cocaine without separating the markets for crack and powder cocaine. However, crack and powder cocaine may represent two very distinct markets with different agents. To allow for potential market differences across

cocaine purchases of five ounces or less. Five ounces translates to 140 grams of cocaine and could be considered wholesale, rather than retail level purchases.

${ }^{35}$ As discussed in the data section, Kuziemko and Levitt (2004) uses per capita drug arrests which includes arrests for both possession and sale of cocaine. Inclusion of both types of arrets does not allow for enforcement on different sides of the market to have distinct effects on pure gram price. 
Table 6: Sensitivity Analysis: Regressions of Pure Gram Price on Enforcement Variables with Variations of Data Exclusion Rules

\begin{tabular}{||l||l|l|l||}
\hline \hline & $\begin{array}{l}\text { Model 1 } \\
\text { weight }<2 \mathrm{~g}\end{array}$ & $\begin{array}{l}\text { Model 2 } \\
1986-1996\end{array}$ & $\begin{array}{l}\text { Model 3 } \\
1990-2000\end{array}$ \\
\hline \hline Enforcement Variable & & & \\
\hline $\begin{array}{l}\text { Median Probation } \\
\text { (Possession) }\end{array}$ & $\begin{array}{l}7.8449 \\
(16.183)\end{array}$ & $\begin{array}{l}-8.2261 \\
(25.232)\end{array}$ & $\begin{array}{l}-4.2383 \\
(16.855)\end{array}$ \\
\hline $\begin{array}{l}\text { Median Sentence } \\
\text { (Possession) }\end{array}$ & $\begin{array}{l}8.7866 \\
(10.514)\end{array}$ & $\begin{array}{l}2.4631 \\
(10.978)\end{array}$ & $\begin{array}{l}5.0614 \\
(7.3697)\end{array}$ \\
\hline $\begin{array}{l}\text { Median Probation } \\
\text { (Sale) }\end{array}$ & 23.272 \\
$(22.460)$ & $\begin{array}{l}47.300 \\
(35.453)\end{array}$ & $\begin{array}{l}22.543 \\
(21.848)\end{array}$ \\
\hline $\begin{array}{l}\text { Median Sentence } \\
\text { (Sale) }\end{array}$ & $\begin{array}{l}15.860 \\
(12.768)\end{array}$ & $\begin{array}{l}9.2830 \\
(13.336)\end{array}$ & $\begin{array}{l}14.896 \\
(10.570)\end{array}$ \\
\hline $\begin{array}{l}\text { Arrest Rate } \\
\text { (Possession) }\end{array}$ & 190.656 & $388.98^{*}$ & $\begin{array}{l}186.02 \\
(261.81)\end{array}$ \\
\hline $\begin{array}{l}\text { Arrest Rate } \\
\text { (Sale) }\end{array}$ & $-802.97^{*}$ & -628.96 & $-716.58^{*}$ \\
$(211.72)$ & $(388.96)$ & $(308.48)$ \\
\hline$R^{2}$ & $(448.28)$ & $0.0205)$ & 0.0192 \\
\hline $\begin{array}{l}\text { Number of } \\
\text { Observations }\end{array}$ & 10811 & 11286 & 8042 \\
\hline \hline
\end{tabular}


Table 7: Sensitivity Analysis(cont): Regressions of Pure Gram Price on Enforcement Variables with Variations of Data Exclusion Rules

\begin{tabular}{|c|c|c|c|}
\hline & $\begin{array}{l}\text { Model } 4 \\
\text { Crack Only }\end{array}$ & $\begin{array}{l}\text { Model } 5 \\
\text { Powder Only }\end{array}$ & $\begin{array}{l}\text { Model } 6 \\
\text { Drop Top/ } \\
\text { Low } 5 \%\end{array}$ \\
\hline \multicolumn{4}{|l|}{ Enforcement Variable } \\
\hline $\begin{array}{l}\text { Median Probation } \\
\text { (Possession) }\end{array}$ & $\begin{array}{l}-3.6652 \\
(13.999)\end{array}$ & $\begin{array}{l}-24.165 \\
(25.090)\end{array}$ & $\begin{array}{l}7.5525 \\
(4.7060)\end{array}$ \\
\hline $\begin{array}{l}\text { Median Sentence } \\
\text { (Possession) }\end{array}$ & $\begin{array}{l}-1.6209 \\
(9.9969)\end{array}$ & $\begin{array}{l}10.7920 \\
(16.975)\end{array}$ & $\begin{array}{l}-0.0140 \\
(2.0298)\end{array}$ \\
\hline $\begin{array}{l}\text { Median Probation } \\
\text { (Sale) }\end{array}$ & $\begin{array}{l}45.1787^{*} \\
(20.1362)\end{array}$ & $\begin{array}{l}46.18301 \\
(40.73403)\end{array}$ & $\begin{array}{l}4.228291 \\
(8.872468)\end{array}$ \\
\hline $\begin{array}{l}\text { Median Sentence } \\
\text { (Sale) }\end{array}$ & $\begin{array}{l}24.992^{*} \\
(9.8689)\end{array}$ & $\begin{array}{l}7.6753 \\
(17.133)\end{array}$ & $\begin{array}{l}4.7406^{*} \\
(2.7685)\end{array}$ \\
\hline $\begin{array}{l}\text { Arrest Rate } \\
\text { (Possession) }\end{array}$ & $\begin{array}{l}270.41 \\
(227.90)\end{array}$ & $\begin{array}{l}527.59 \\
()\end{array}$ & $\begin{array}{l}135.42^{* *} \\
(50.748)\end{array}$ \\
\hline $\begin{array}{l}\text { Arrest Rate } \\
\text { (Sale) }\end{array}$ & $\begin{array}{l}-676.53^{*} \\
(193.40)\end{array}$ & $\begin{array}{l}57.239 \\
(819.52)\end{array}$ & $\begin{array}{l}-227.81^{* *} \\
(72.465)\end{array}$ \\
\hline$R^{2}$ & 0.0286 & 0.0319 & 0.1201 \\
\hline $\begin{array}{l}\text { Number of } \\
\text { Observations }\end{array}$ & 9612 & 3273 & 11427 \\
\hline
\end{tabular}

Note: Year and state fixed effects are included but not reported. Errors are clustered at the county level.

*Significant at the 10 percent level. ${ }^{*}$ Significant at the 5 percent level. 
types of drug, the analysis of Table 5 is repeated with the data separated into observations of crack cocaine and powder cocaine. Columns one and two of Table 7 present the coefficient estimates. None of the coefficient estimates on consumer enforcement variables (sentence or arrest rate) are significantly different from zero when looking solely at crack cocaine observations. However, all of the coefficients on dealer enforcement variables are significant though not entirely consistent with the notion of dealer arrest avoidance; the arrest rate for sale of cocaine is negative, however the coefficient on sentence for sale of cocaine is positive. This empirical result shows the need for a model where probability of arrest and sentence enter the dealer's objective function separately. When observations are limited to powder cocaine observations, none of the enforcement coefficients are significant.

The final column of Table 7 presents the results when I use data exclusion rules that are similar to Kuziemko and Levitt (2004). ${ }^{36}$ The highest and lowest five percent of pure gram prices are dropped, leaving 11427 observations. Dealer sentence length is the only penalty coefficient that is significant and positive. The coefficient estimate is positive and significant for consumer arrest rate and negative and significant for expected dealer arrest rate which are consistent with the implications derived from arrest avoidance.

One of the major departures in this paper from Kuziemko and Levitt (2004) and Bushway, Caulkins and Reuter (2003) is the treatment of penalties. I discount future periods and use the transformed sentence variables in the analysis above. To follow the previous literature, I repeat the analysis of Table 5 using the median county sentence without discounting. However, sentences are truncated so that any person receiving more than 50 years is recoded at 50 years. The coefficient estimates do not change in sign and the arrest rate for sale becomes significant at a 1 percent level.

\section{Conclusion}

This research proposes a different way of treating law enforcement focused on dealers and consumers and estimates the sign of the relationships between pure gram price and agent-specific enforcement. Previous empirical research of the effect of law enforcement on

\footnotetext{
${ }^{36}$ The data is not identical to Kuziemko and Levitt (2004) because they calculate state-wide pure gram price and I use all observations recorded in that area.
} 
cocaine price has provided limited results. Kuziemko and Levitt (2004) report a positive and highly significant relationship between their measure of state level probability of arrest pure gram price. Bushway, Caulkins and Reuter (2003) present a small and significantly positive relationship between expected sentence for dealers and pure gram price. Neither allows for enforcement to have a separate effect on consumer behavior, which traditional theory suggests will have a conflicting effect on price. Future research should be careful to discuss how consumer behavior impacts the cocaine market.

This paper also introduces arrest avoidance as an alternative method for enforcement to impact pure gram price for both consumers and dealers. If cocaine dealers maximize profit while avoiding arrest, then the pure gram price chosen by dealer profit maximization may be decreasing in the penalty (defined as the expected sentence length for sale of cocaine). Consumers may avoid arrest by minimizing the number of interactions with dealers which implies that pure gram price is increasing in the possession enforcement variables.

Using cocaine purchase data and legal enforcement data I examine the relationship between enforcement and pure gram price. The pure gram price is regressed on the enforcement variables and demographic covariates with year and state fixed effects and errors clustered by county. The coefficient on expected dealer enforcement is negative and significant, providing empirical support that the (negative) impact of arrest avoidance overwhelms the (positive) impact of high fixed costs on price. The coefficients on expected consumer enforcement variables are positive and some are significant, consistent with a simple model of consumer search. Given opposing signs of the coefficients, an increase in total enforcement (on both consumers and dealers) has an undetermined effect on pure gram price.

I also provide some evidence that the pure gram prices of crack cocaine and powder cocaine respond to changes in enforcement differently. Unfortunately, the current enforcement data do not provide information concerning the specific type or form of drug the consumer (or dealer) is arrested and sentenced for buying (or selling). If the two forms of cocaine (crack and powder) represent different markets, researchers should be careful to separate the observations when performing analysis.

The important result of this analysis is that movement of pure gram price does not provide an easy answer to whether or not current enforcement levels are successful. Researchers 
should also think about how enforcement may enter into the decision-making process in a non-traditional manner. This paper demonstrates that there is room for more research to be conducted on the behavior of consumers and dealers in an illegal drug market. An interesting avenue for future research includes equilibrium models of behavior; new research may expand the analysis of law enforcement and measure the effect it has (if any) on the interdependent choices of dealers and consumers in the retail cocaine market. 


\section{References}

[1] Abt Associates (2001). The Price of Illicit Drugs: 1981 through the Second Quarter of 2000. Prepared for the Office of National Drug Control Policy (ONDCP).

[2] Buchinsky, Moshe (1997). Recent Advances in Quantile Regression Models: A Practical Guideline for Empirical Research. Journal of Human Resources. 33(1):88-126.

[3] Burrus, Robert T. Jr. (2005). The Impact of Weight-Based Penalties on Drug Purity and Demand: A Theoretical Analysis. Forthcoming: Eastern Economic Journal.

[4] Bushway, Shawn, Jonathan Caulkins and Peter Reuter (2003). Does State and Local Drug Enforcement Raise Cocaine Prices? Working Paper.

[5] Caulkins, Jonathan P., Bruce Johnson, Angela Taylor, and Lowell Taylor (1999). What Drug Dealers Tell Us About Their Costs of Doing Business. Journal of Drug Issues. 29(2): 323-340.

[6] Davies, Ronald B. (2005). Mandatory Minimum Sentencing and the Purity of Cocaine and Heroin. Working Paper.

[7] DeSimone, Jeff (2001). The Effect of Cocaine Prices on Crime. Economic Inquiry. 39(4): 627-643.

[8] DeSimone, Jeff and Matthew Farrelly (2003). Price and Enforcement Effects on Cocaine and Marijuana Demand. Economic Inquiry. 41(1): 98-115

[9] DiNardo, John (1993). Law Enforcement, the Price of Cocaine and Cocaine Use. Mathematical and Computer Modelling. 17(2): 53-64.

[10] Freeborn, Beth (2003). An Equilibrium Search Model of the Retail Cocaine Market and Drug Law Enforcement. Working Paper.

[11] Grossman, Michael and Frank Chaloupka (1998). The Demand for Cocaine by Young Adults: A Rational Addiction Approach. Journal of Health Economics. 17: 427-474. 
[12] Horowitz, Joel (2002). Should the DEA's STRIDE data be used for economic analyses of markets for illegal drugs? Journal of the American Statistical Association. 96: 12541262.

[13] Kuziemko, Ilyana and Steven D. Levitt (2004). An Empirical Analysis of Imprisoning Drug Offenders. Journal of Public Economics 88: 2043-2066.

[14] Levitt, Steven D. and Sudhir Alladi Venkatesh (2000). An Economic Analysis of a DrugSelling Gang's Finances. Quarterly Journal of Economics. 115(3): 755-789.

[15] Listokin, Yair (2003). Crime and (with a Lag) Punishment: Equitable Sentencing and the Implications of Discounting. Working Paper. http://ssrn.com/abstract=434640

[16] National Research Council (2001). Informing America's Policy on Illegal Drugs: What We Don't Know Keeps Hurting Us Committee on Data and Research for Policy on Illegal Drugs. Manski, Charles, John Pepper and Carol Petrie, editors. National Academy Press, Washington, D.C.

[17] Office of National Drug Control Policy. See http://www.whitehousedrugpolicy.gov.

[18] Office of National Drug Control Policy (2004). The Price and Purity of Illicit Drugs: 1981 Through the Second Quarter of 2003. Washington DC: Executive Office of the President (Publication Number NCJ 207768).

[19] Pagan, Adrian and Aman Ullah (1999). Nonparametric Econometrics. Cambridge University Press.

[20] Polinsky, A. Mitchell and Steven Shavell (1999a). On the Disutility and Discounting of Imprisonment and the Theory of Deterrence. Journal of Legal Studies 28: 1-16.

[21] Polinsky, A. Mitchell and Steven Shavell (1999b). The Economic Theory of Public Enforcement of Law. Journal of Economic Literature 38(1): 45-76.

[22] Riley, K. Jack (1997). Crack, Powder Cocaine, and Heroin: Drug Purchase and Use Patterns in Six U.S. Cities. Report prepared for the Office of National Drug Control Policy. 
[23] System to Retrieve Information from Drug Evidence (STRIDE), Drug Enforcement Agency (DEA). Made available through the Freedom of Information Act. Request Number: 01-1799-F

[24] Saffer, Henry and Frank Chaloupka (1999). The Demand for Illicit Drugs. Economic Inquiry 37(3): 401-411.

[25] Sevigny and Caulkins (2004). Kingpins or Mules: An Analysis of Drug Offenders Incarcerated in Federal and State Prisons. Criminology and Public Policy. 3(3): 401-434.

\section{A Appendix}

\section{A.1 Transformation of Penalty Data}

My complete data set matches county level prison sentences (and probation terms) and county level arrest rates to the purchase data (matched by FIPS code and year). However, a good deal of the purchase data comes from counties that are not represented in the NJRP or UCR. NJRP data are only collected every two years with data on drug sale and possession available from 1986-1998. If the mean penalty was calculated for each county-year and matched to the drug purchase data, the total number of matched observations would be small. For this reason, I assume the values of median sentence length are stable over time and assign the overall county median to all years. Prior to assigning the missing county-year values, I test to see how stable county sentencing behavior is over time.

\section{A.1.1 Hypothesis Test}

First, let me introduce some new notation. Let

$$
y_{i j t}=\delta_{i t}+\varepsilon_{i j t}
$$

where $y_{i j t}$ is the $j^{t h}$ sentence in the $i^{\text {th }}$ county at time $t$. The median for county $i$ at time $t$ is given by $\delta_{i t}$ and the error $\varepsilon_{i j t}$ is assumed to have some unknown distribution $F(0, \sigma)$. There are $n$ total observations of sentences. 
I wish to test the hypothesis that county sentencing behavior does not change over time:

$$
\begin{aligned}
& H_{0}: \quad \delta_{i 1}=\delta_{i 2}=\ldots=\delta_{i T} \\
& H_{A}: \quad \delta_{i 1} \neq \delta_{i 2} \neq \ldots \neq \delta_{i T} \\
& \forall i=1, \ldots, I
\end{aligned}
$$

If the null is rejected, then I cannot assign the county median to all years of purchase data within that county.

The test statistic for this hypothesis test is

$$
z_{i}=\left(A_{i} \widehat{\delta}_{i}\right)^{\prime}\left[A_{i} D_{i}(\delta) A_{i}^{\prime}\right]^{-1}\left(A_{i} \widehat{\delta}_{i}\right) \sim \chi_{\left(n_{i}\right)}^{2}
$$

where $\widehat{\delta}_{i}$ is the vector of estimated year medians for county $i$, and $D_{i}(\delta)$ is the $n_{i} \times n_{i}$ diagonal covariance matrix of the medians. $A_{i}$ is an $\left(n_{i}-1\right) \times\left(n_{i}\right)$ matrix of the form where $n_{i}$ is the number of years of available data in county $i$. For instance, if there were 5 years of penalty data available for county $i$, then $A_{i}$ would take the form:

$$
A_{i}=\left[\begin{array}{ccccc}
1 & -1 & \cdot & \cdot & \cdot \\
\cdot & 1 & -1 & \cdot & \cdot \\
\cdot & \cdot & 1 & -1 & \cdot \\
\cdot & \cdot & \cdot & 1 & -1
\end{array}\right]
$$

$z_{i}$ is distributed chi-squared with $\left(n_{i}\right)$ degrees of freedom. ${ }^{37}$

In order to find the diagonal terms of $D_{i}(\delta)$, I need to find the variance of each countytime median. Following Bushinsky (1997), the formula for the estimate of the variance of a median is:

$$
\widehat{\sigma_{i t}}=\frac{1}{4 n_{i t} * f^{2}(0)}
$$

where $n_{i t}$ is the number of observations in county-time combination $i$ - $t$, and $f(0)$ is the density of $\varepsilon$ evaluated at 0 .

However, this density $f$ is unknown. Rather than make any assumptions regarding the distribution of $\varepsilon$, I estimate $f(0)$ using a kernel estimator. Following the Rosenblatt-Parzen

\footnotetext{
${ }^{37}$ The degrees of freedom will depend on the dimensions of the covariance matrix. For the possession data, this is 961 degrees of freedom. 961 is the total number of distinct county-time combinations (several missing counties and years). For the sale data, the degrees of freedom is 1635 .
} 
kernel estimator in Pagan and Ullah (1999) the kernel estimator is:

$$
\widehat{f(0)}=\frac{1}{n * h} \sum_{l}^{n} K\left(\frac{\varepsilon_{l}}{h}\right)
$$

where $K$ is the standard normal kernel, $K(\psi)=(2 \pi)^{-\frac{1}{2}} \exp \left(-.5 \psi^{2}\right), n$ is the sample size, and $h$ is the bandwidth which is a function of the sample size and goes to 0 as $n \rightarrow \infty$.

Using the statistical program SAS, I find the bandwidth that minimizes the AMISE (approximate mean integrated squared error) is $h=1.0417$ with $n=90356$ for possession sentence data. The bandwidth for sale data is $h=1.9481$ and $n=123973$. I can calculate $f(0)$, and $f^{2}(0)$.

$$
\begin{array}{r}
\text { Possession : } f(0)=0.08555 \\
\text { Sale }: \quad f(0)=0.05250
\end{array}
$$

I calculate a vector of variances using formula (4). Given $\widehat{\sigma_{i t}}$, I construct the $D_{i}(\delta)$ matrix, and construct the test statistic $z_{i}$ for each county. The value of the critical value $t$ varies over counties due to variation in the number of years available for a given county. The null is not rejected for any county in the penalty data. Therefore, county penalty behavior is stable over time, and I assign the county median sentence to all purchase observations made in that county.

\section{A.2 Probability of Arrest Calculation}

This section describes the data necessary to calculate the probability of arrest for sale of cocaine and arrest for possession of cocaine. Recall that the probability is the number of arrests made for a given drug offense divided by the number of drug encounters within a market.

\section{A.2.1 Numerator (Arrest Rates): UCR}

The FBI's annual Uniform Crime Reporting (UCR) program provides a nationwide view of crime based on statistics submitted by law enforcement agencies at the city, county and state level. ${ }^{38}$ The number of arrests from the UCR data acts as a numerator in the calculation

\footnotetext{
${ }^{38}$ The FBI does not separately report cocaine and opium related arrests. This group definition of arrests may overestimate the probability of arrest.
} 
of probability of arrest for each offense (possession or sale) in county. The probability of arrest from the UCR data is matched to the STRIDE and NJRP penalty data by county and year.

\section{A.2.2 Denominator (Number of Encounters): E}

I calculate the number of encounters as the number of cocaine consumers multiplied by the average number of purchases the average consumer makes.

National Household Survey on Drug Abuse: NHSDA I use information on drug use from the National Household Survey on Drug Abuse (NHSDA) to construct the denominator in the probability of arrest.

The NHSDA is a yearly survey designed to produce drug and alcohol use incidence and prevalence estimates and report the consequences and patterns of use and abuse in the general U.S. civilian population aged 12 and older. Questions include age at first use, as well as lifetime, annual, and past-month usage for a multitude of drugs, including cocaine and crack. Demographic data include gender, race, age, ethnicity, educational level, and population density. The publicly available data provided by the NHSDA does not include a geographic identifier. ${ }^{39}$

In order to get an estimate of the number of consumers in a particular county, I use a linear probability model to estimate the probability of use given the demographic variables available in the NHSDA. I repeat this process separately for each year. ${ }^{40}$

Census: 1990 and 2000 The linear probability regression results can be used to estimate the probability that a person uses cocaine. In order to construct the number of users for a given county, I use demographic information from the 1990 and 2000 Census. For each year 1986-2001, I impute the proportions of the population that are male, never married, black, age 16-20, age 35-49, and have a high school diploma or a GED. Given the year-specific coefficient estimates from the linear probability model, I estimate the probability

\footnotetext{
${ }^{39}$ As discussed previously, if the NHSDA included a county-FIPS identifier, I could calculate an estimate of the number of consumers in the particular county based on observable demographic characteristics.

${ }^{40}$ The null hypothesis that consumer behavior based on demographic information was stable across years was rejected at the $5 \%$ level.
} 
that an average citizen in each county is a cocaine consumer. Multiplying this probability by the total population of that county in the particular year provides an estimate of the total number of consumers in each county for each year. 